The greatest demand for increased funding has been due to moving children with special educational needs out of special schools into normal schools. This has appreciably increased the travelling time for both the school doctors and the community therapists. It has also meant that teachers in normal schools have had to be counselled about the needs of handicapped children. Suitable aids have had to be made available for use within the school and it has frequently not been clear whether the health or the education authority is responsible for purchasing and maintaining this equipment.

In summary implementation of the Act has meant that, while certain children do stand to benefit educationally, an additional load has been placed on an already strained state educational system by integrating children with special needs into normal schools. On the medical side the government's new legislation has put pressure on our already chronically underfunded NHS and, more specifically, in one of its sections-children with special needs-that has always had low priority. Sadly, the failure to provide extra funds has in some districts resulted in a deterioration of services for these children.

J A MACFARLANE

Consultant Paediatrician (Child Health),

Department of Community Medicine,

Radcliffe Infirmary,

Oxford OX2 6HE

1 Education Act 1981. London: HMSO, 1981

2 Warnock HM. Special educational needs: report of the Committee of Enquiny into the Education of Handicapped Children and Young People. London: HMSO, 1978.

\section{Prevention of hazardous drinking: the value of laboratory tests}

In its first issue this year the $B M \mathcal{F}$ bleakly recognised that no changes will be forthcoming in the immediate future in government fiscal policy to help prevent the current epidemic of alcoholism and alcohol related disease. ${ }^{1}$ Our effort should, therefore, be aimed at the early detection of hazardous drinking, before patients have become dependent on alcohol or sustained organ damage, and when their behaviour should be easier to modify. Exactly what constitutes hazardous drinking has now been agreed-a regular daily consumption of over $80 \mathrm{~g}$ alcohol in men and $40 \mathrm{~g}$ in women-but even lower levels of consumption may be harmful. Adverse effects on blood pressure in middle aged men may be seen at consumption levels of $10-25 \mathrm{~g}$ a day, ${ }^{2}$ while in pregnant women $10-20 \mathrm{~g}$ a day increases the risk of producing an infant with growth retardation. ${ }^{3}$ Early detection of hazardous drinking remains difficult. Doctors often fail to take an adequate drinking history ${ }^{4}$ and self reported alcohol consumption is notoriously underestimated. 5 A detailed assessment of the quantity and frequency of alcohol consumed in the preceding week (obtained by either structured interview or self administered questionnaire) may overcome inaccurate recall over a longer period and is fairly representative of the average weekly consumption.$^{67}$ Nevertheless, some patients deceive their doctors, and corroborative evidence should be sought from relatives and friends.
A range of well validated questionnaires based on abnormal drinking behaviour and attitudes-the most popular of which are the Michigan alcoholism screening test, the CAGE questionnaire, and the REICH interview-have proved useful in screening for alcohol abuse in high risk populations such as general hospital or psychiatric inpatients, but they have a limited place in the general community. ${ }^{8.10}$ Moreover, these questionnaires do not detect people who do not see their drinking as a problem.

The past decade has witnessed a search for more objective biological markers to detect the hazardous drinker who underreports his consumption or does not see his drinking as a problem. A blood alcohol concentration of over $32.5 \mathrm{mmol} / 1(150 \mathrm{mg} / 100 \mathrm{ml})$ in a patient who is not obviously intoxicated indicates both tolerance and hazardous drinking. ${ }^{11}$ The measurement of alcohol in the innovative sweat patch has been reported to identify people drinking at least $0.5 \mathrm{~g} / \mathrm{kg}$ a day with $100 \%$ sensitivity and specificity, ${ }^{12}$ but this has not been confirmed. ${ }^{13}$ Serum $\gamma$-glutamyltransferase activity and the mean red cell volume have emerged as the most sensitive commonly available laboratory markers. Among populations of general medical or psychiatric patients at high risk the sensitivity of $\gamma$-glutamyltransferase activity in detecting alcohol abuse is reported as between $36 \%{ }^{9}$ and $90 \%,{ }^{14}$ and that of the mean red cell volume from $26 \%{ }^{15}$ to $89 \% .{ }^{16}$ In populations at low risk taken from health screening programmes the sensitivity of these tests is reported to be as low as $18 \%{ }^{17}$ and $10 \%{ }^{18}$ respectively.

$\gamma$-Glutamyltransferase activity is relatively non-specific and may be affected by body weight, non-alcoholic liver disease, and microsomal enzyme inducing drugs. ${ }^{19}$ The wide variation in sensitivity of $\gamma$-glutamyltransferase activity and the mean red cell volume is due not only to the differing subpopulations of alcoholics studied but also to the different methods of assessing alcohol consumption, the heterogeneous definition of alcohol abuse, and differing normal reference ranges: reported upper limits of reference for the mean red cell volume range from $90^{20}$ to $98 \mathrm{fl} .{ }^{15}$ (Studies using the lower limit tend to have high sensitivity at the expense of specificity.) $\gamma$-Glutamyltransferase activity tends to revert to normal if alcohol abuse is long standing, the highest activities being observed in the first five years. ${ }^{21}$ Furthermore, there is a large individual variation of response to alcohol: a raised $\gamma$-glutamyltransferase activity will not be observed in all hazardous drinkers and will be observed in a proportion of social drinkers.

The application of logistic regression or discriminant function analysis to combinations of biological markers, with or without the inclusion of scores derived from psychosocial or trauma questionnaires, improves sensitivity. ${ }^{22} 23$ In a recent study of 7735 middle aged men Shaper and colleagues, using a discriminant score based on five laboratory markers, found an improved sensitivity over $\gamma$-glutamyltransferase activity alone but highlighted the large biological variation in response to alcohol. They suggested that the discriminant score may be used to identify people in whom excessive consumption of alcohol results in biochemical and haematological abnormalities and thus who are potentially at increased risk of developing alcohol related disease. ${ }^{24}$ This suggestion is supported by a study of middle aged men in a health screening programme where those with a $\gamma$-glutamyltransferase activity in the top quintile of distribution were six to seven times more likely to die within four years (median follow up two years) than those with values in the lowest quintile. ${ }^{25}$ As part of a preventive medicine programme a special outpatient clinic has been set up for those with 
increased $\gamma$-glutamyltransferase activities (three quarters of whom were hazardous drinkers), and this test is under evaluation as a tool for further investigation, treatment, and control of high alcohol consumption. ${ }^{26}$

In conclusion, commonly available laboratory markers, either individually or in combination, are not effective screening tests for detecting hazardous drinking but do identify those subjects whose alcohol consumption is producing possibly harmful metabolic changes. Further studies are needed to evaluate the place of other promising biological markers such as red blood cell aldehyde dehydrogenase activity, ${ }^{27}$ serum desialotransferrin, ${ }^{28}$ and serum mitochondrial aspartate aminotransferase activity. ${ }^{29}$

\section{RICHARD D JOHNSON Honorary lecturer}

\section{ROGER WILLIAMS
Director}

Liver Unit,

King's College Hospital,

London SE5 9RS

1 Paton A. The politics of alcohol. BrMed f 1985;290:1-2.

2 Mitchell PI, Morgan MJ, Boadle DJ, et al. Role of alcohol in the aetiology of hypertension. Med $\mathcal{f}$ Aust 1980;67:198-200.

3 Mills JL, Graubard BI, Harley EE, Rhoado GG, Berendes HW. Maternal alcohol consumption and birth weight. How much drinking during pregnancy is safe? JAMA 1984;252:1875-9.

4 Barrison IG, Viola L, Murray-Lyon IM. Do housemen take an adequate drinking history? $\mathrm{Br}$ Med f 1980;281:1040.

Watson CG, Tilleskjor C, Hoodecheck-Schow EA, Pucell J, Jacobs L. Do alcoholics give valid atson CG, Tilleskjor C, Hoodecheck-Schow
self-reports? I Stud Alcohol 1984;45:344-8.

6 Robinson D, Monk C, Bailey A. The relationship between serum gammaglutamyl transpeptidase obinson D, Monk C, Bailey A. The relationship between serum gammaglutamyl transpeptidel and reported alcohol consumption in healthy men. J Stud Alcohol 1979;40:896-901.
level
7 Chick J, Kreitman N, Plant M. Saving face? Survey respondents who claim their last week's drinking was atypical. Drug Alcohol Depend 1981;7:265-72.

8 Gibbs LE. Validity and reliability of the Michigan alcoholism screening test: a review. Drug Alcohol Depend 1983;12:279-85.

9 Bernadt MW, Mumford J, Taylor C, Smith B, Murray RM. Comparison of questionnaire and laboratory tests in the detection of excessive drinking and alcoholism. Lancet 1982;i:325-8.

10 Saunders WM, Kershaw PW. Screening tests for alcoholism-findings from a community study. Br f Addict 1980;75:37.41.

11 Holt S, Skinner HA, Israel Y. Early identification of alcohol abuse: 2: clinical and laboratory indicators. Can Med Assoc $\mathcal{F}$ 1981;124:1279-95.

12 Phillips $M$. Sweat-patch testing detects inaccurate self-reports of alcohol consumption. Alcoholism: Clinical and Experimental Research 1984;8:51-3.

13 Phillips ELR, Little RE, Hillman RS, Labbe RF, Campbell C. A field test of the sweat patch. Alcoholism: Clinical and Experimental Research 1984;8:233-7.

14 Rosalki SB, Ran D. Serum $\gamma$-glutamyl transpeptidase activity in alcoholism. Clin Chim Acta 1972;39:41-7.

15 Lloyd G, Chick J, Crombie E. Screening for problem drinkers among medical inpatients. Drug Alcohol Depend 1982;10:355-9.

16 Wu A, Chanarin I, Levy AJ. Macrocytosis of chronic alcoholism. Lancet 1974;i:829-30

17 Clark PMS, Holder R, Mullet M, Whitehead TP. Sensitivity and specificity of laboratory tests for alcohol abuse. Alcohol and Alcoholism 1983;18:261-9.

18 Bliding G, Bliding $\AA$, Törnqvist $\mathrm{C}$. The appropriateness of laboratory tests in tracing young heavy drinkers. Drug Alcohol Depend 1982;10:153-8.

19 Penn R, Worthington DJ. Is serum $\gamma$-glutamyltransferase a misleading test? Br Med f 1983;286: $531-5$.

20 Whitfield JB, Hensley WJ, Bryden D, Gallagher H. Some laboratory correlates of drinking habits. Ann Clin Biochem 1978;15:297-303.

21 Wadstein J, Skude G. Serum ethanol, hepatic enzymes and length of debauch in chronic alcoholics. Acta Med Scand 1979;205:317-8.

22 Bernadt MW, Mumford J, Murray RM. A discriminant-function analysis of screening tests for excessive drinking and alcoholism. I S Stud Alcohol 1984;45:81-6.

23 Skinner HA, Holt S, Schuller R, Roy J, Israel Y. Identification of alcohol abuse using laboratory Skinner HA, Holt S, Schuller R, Roy J, Israel Y. Identification of
tests and a history of trauma. Ann Intern Med 1984;101:847-51.

24 Shaper AG, Pocock SJ, Ashby D, Walker M, Whitehead TP. Biochemical and haematological response to alcohol intake. Ann Clin Biochem 1985;22:50-61

25 Peterson B, Kristenson H, Sternby NH, et al. Alcohol consumption and premature death in middle-aged men. BrMed f 1980;280:1403-6.

26 Kristenson $\mathrm{H}$, Trell E, Hood B. Serum $\gamma$-glutamyltransferase in screening and continuous control of heavy drinking in middle-aged men. Am $\mathcal{F}$ Epidemiol 1981;114:862-72.

27 Agarwal DP, Tobar-Rojas L, Harada S, Werner-Goedde H. Comparative study of erythrocyte aldehyde dehydrogenase in alcoholics and control subjects. Pharmacol Biochem Behav 1983;18(suppl 1):89-95.

28 Stibler $\mathrm{H}$, Borg S, Blanche C, Joustra $\mathbf{M}$. Desialotransferrin-a new routine method for early detection of high alcohol consumption. Alcoholism: Clinical and Experimental Research $1984 ; 8: 121$.

29 Nalpas B, Vassault A, Le Guillou A, et al. Serum activity of mitochondrial aspartate aminor-ansferase: a sensitive marker of alcoholism with or without alcoholic hepatitis. Hepatology 1984;4:893-6.
Many clinicians are worried that prolonged treatment with powerful antisecretory drugs may increase patients' chances of developing gastric cancer, either through hypochlorhydria favouring bacterial growth or through the direct carcinogenic effect of drug molecules. Whether these fears are justified is not clear. We do, however, know that patients with pernicious anaemia have an increased risk of developing gastric cancer, and that patients who have had gastric resections for peptic ulcer may also be at risk. The reasons for this are not understood, but may include mucosal instability associated with atrophic gastritis leading to dysplasia and then gastric cancer, or reduced gastric acidity favouring bacterial growth in the stomach and then the formation of carcinogenic nitrosamines in the presence of ingested nitrates and nitrites.

Four sorts of test are in use to screen drugs for possible carcinogenic effects, but of these no single one may be relied on to reject what is potentially dangerous and to select all, and only, those drugs that are safe.

Drugs are examined for mutagenic activity by searching for changes in the ability of bacterial cultures to survive in media deficient of nutrients when concurrently exposed to the drug. There is no certainty, however, that such screening identifies all potentially mutagenic compounds.

To take this a stage further, prolonged studies in animals are carried out with a dose often 100 times or more than the expected dose in man for the duration of the animal's life. Although efforts are made to ensure that the metabolic pathways of the animals studied do not differ too much from those of man, the meaning of positive or negative results is not clear. Gross overdosing during a two year period in an animal which may be more or less susceptible to cancer is of questionable relevance to intermittent low dose treatment in man over an indefinite period. 